ISSN 1979-5572 (print) | ISSN 2541-6480 (online)

http://ejurnal.iainpare.ac.id/index.php/kuriositas

\title{
KURIOSITAS
}

Media Komunikasi Sosial dan Keagamaan

Volume 12

No.2, Des 2019

Halaman 111 - 122

\section{Modal Sosial Dan Integrasi Sosial: Asimilasi Dan Akulturasi Budaya Masyarakat Multikultural Di Polewali Mandar, Sulawesi Barat}

\author{
Abd. Halim K. ${ }^{\text {; }}$ Mahyuddin ${ }^{2}$ \\ 1,2IAIN Parepare \\ habdhalimk@iainpare.ac.id
}

\begin{abstract}
This research aims to explain the role of the social capital of local community in integration process of inter-sociocultural. Discourse of multicultural society is important to be known because the difference of social community has a big potential to be a social disintegration. Nevertheless, the social life, which has different of culture, was not always occurred the disunion. Local wisdoms of community as social capital could facilitate an adhesive social so that they lived in social harmony. The type of this research is descriptive qualitative describing inter-ethnic social integration by taking place Wonomulyo, PolewaliMandar, West Sulawesi, one of provinces in Indonesia. The data collection techniques were observation, depth interview, and documentation. Withdrawal informants were done by purposive sampling. The theory used in this study was social capital by Robert Putnam and Pierre Bourdieu. This theory explained social capital by studying social habitus of local community. The results showed that social capital of local community had a role on processing integration of community that differ ethnic and culture. As a result, the ethnic groups integrated well was characterized by social relationships among ethnic groups remain in a stable state and bound in the integration of groups. Then, the equilibrium of groups created assimilation and acculturation of culture in the society. The ethnic groups cooperated each other in economy and social activity and there was no social conflict among them.
\end{abstract}

Keywords: Social Integration, Social Capital, Assimilation, Acculturation and Multicultural Societies. 


\section{PENDAHULUAN}

Hubungan antaretnis di Indonesia merupakan salah fenomena yang sering diperbincangkan. Persoalan ini berhubungan erat dengan keberagaman suku bangsa di setiap daerah yang hampir setiap suku memiliki karakter budaya, tradisi dan agama yang berbeda tetapi hidup secara berdampingan (Syafar, 2019). Di sisi lain kelompok-kelompok masyarakat yang memiliki ragam identitas budaya dan agama, dalam banyak wajah seringkali bersifat kontestatif serta melahirkan sikap primordial dan etnosentrisme yang berbahaya bagi pembangunan perdamaian (Ernas, 2018),(Jubba, 2019).

Saat ini setiap daerah diperhadapkan dengan sebuah kenyataan bahwa individu atau kelompok yang menetap dalam suatu wilayah merupakan kelompok masyarakat yang berasal dari latar belakang budaya yang berbeda. Bersamaan dengan itu, potensi terjadinya disintegrasi sosial juga terbuka lebar di mana keadaan ini berpeluang melahirkan gesekan sosial dan budaya yang mengancam sendi-sendi keharmonian sosial (Syamsiatun, 2014), (Mahyuddin, 2018), (Mahyuddin, 2019).

Namun demikian, perlu diperhatikan bahwa tidak semua masyarakat yang memiliki keanekaragaman etnis dan budaya bahkan agama mengalami perpecahan. Masyarakat multikultural dalam banyak tempat juga banyak menyemai integrasi sosial (Raga, 2013); (Varanida, 2016). Integrasi tersebut berwujud dalam keadaan anggota masyarakatnya yang berada dalam kondisi stabil dan tetap terikat dalam kesatuan kelompok meskipun secara identitas memiliki perbedaan yang mencolok.

Sebagaimana halnya di Polewali Mandar tepatnya di Kecamatan Wonomulyo, masyarakat di daerah ini secara garis besar terdapat empat etnis yang mendiami wilayah tersebut, yaitu etnis Mandar, Bugis, Jawa, dan Toraja. Keberadaan kelompok etnik dalam satu lokasi dengan latar belakang budaya yang berbeda, ternyata dapat terintegrasi menjadi satu kesatuan yang serasi. Hal ini ditandai dengan hubungan sosial di antara kelompok etnis tetap terjalin hubungan yang harmonis dan sangat jarang didapatkan konflik-konflik sosial yang di latar belakangi oleh perbedaaan kebudayaan (Iqbal, 2015).

Fenomena integrasi ini tidak dapat dipisahkan dari peran modal sosial masyarakat. Modal sosial sebagaimana terminologi yang dikemukakan oleh Robert D. Putnam bahwa ia merupakan bagian dari organisasi sosial yang mampu memfasilitasi tindakan kolektif. Melalui arena modal sosial (netwotks, norms, trust), tiap-tiap individu atau kelompok dapat membuka diri untuk berinteraksi satu sama lain (Field,2010). 
Terintegrasinya kelompok-kelompok etnik di Wonomulyo tergambar dalam keselarasan hubungan sosial di antara kelompok etnis yang mengurangi perbedaan identitas serta menerima bagian budaya kelompok lain menjadi bahagian dari budayanya tetapi tidak menghilangkan identitas budaya masingmasing. Menariknya, perbedaan etnis, bahasa, budaya bahkan agama tidak menjadikan mereka saling bertolak belakang dalam kehidupan sosialnya. Sebaliknya, mereka tetap hidup dalam keadaan rukun, menjunjung tinggi nilainilai kebersamaan serta bersikap saling menghargai walaupun memiliki perbedaan-perbedaan secara sosial dan budaya.

Berdasarkan penjelasan di atas, tulisan ini akan menjawab atau mendiskusikan beberapa pertanyaan berikut ini; 1). Bagaimana peran modal sosial masyarakat lokal dalam proses integrasi sosial masyarakat yang berbeda secara identitas etnis dan budaya? Bagaimana bentuk integrasi sosial yang terjadi di dalam kehidupan sosial antarkelompok etnik?

\section{METODE PENELITIAN}

Penelitian ini menggunakan penelitian kualitatif dengan pendekatan studi kasus. Penulis mendapatkan pandangan-pandangan umum dari masyarakat tentang peran modal sosial masyarakat lokal dalam proses integrasi sosial masyarakat multietnik di Kecamatan Wonomulyo Kabupaten Polewali Mandar Sulawesi Barat. Pemilihan informan dalam penelitian ini menggunakan pusposive sampling. Kriteria informannya adalah; (1) Kelompok etnis yang berinteraksi dan berkomunikasi serta bekerja sama secara intensive dengan kelompok etnik lain. (2) Identitas etnik Bugis, Mandar, Jawa, dan Toraja untuk memberikan kebutuhan informasi sesuai dengan tujuan penelitian ini.

Mengingat bahwa penelitian ini merupakan jenis penelitian kualitatif maka data-data yang dikumpulkan dalam penelitian ini diperoleh dengan metode-metode yang lazim dalam penelitian kualitatif yaitu observasi, wawancara mendalam dan studi kepustakaan (Gunawan, 2013). Data-data yang telah dikumpulkan tersebut selanjutnya dianalisis dengan menggunakan model analisis Miles dan Haberman.

\section{Seremoni Budaya Lokal sebagai Modal Sosial Membangun Integrasi Sosial}

Modal sosial ialah sebuah terminologi yang diperkenalkan oleh Robert D. Putnam, salah seorang ilmuah politik berkebangsaan Amerika. Putnam mendefenisikan modal sosial sebagai kepercayaan (trust), norma (norms) dan jaringan (networks) yang dapat memperbaiki efesiensi masyarakat dengan 
menfasilitasi tindakan terkoordinasi (Field, 2010). Modal sosial dipercaya dapat membentuk solidaritas yang memungkinkan individu menjalin hubungan sosial terus menerus yang dapat dimanfaatkan dalam jangka pendek maupun jangka panjang (Li, Savage and Warde, 2008).

Selaras dengan yang tersebut di atas, Sunyoto Usman mengemukakan bahwa modal sosial lazim membentuk relasi sosial antarindividu atau kelompok yang membentuk jejaring sosial (net) yang diikat oleh hubungan pertemanan (frienship), kekeluargaan (kinship), dan melembagakan hubungan tatap muka (face to face relationships). Dalam bentuk hubungan semacam ini, tumbuh kepercayaan dan komitmen pertemanan yang memperkuat jalinan hubungan sosial untuk mencapai tujuan bersama (Usman, 2015).

Salah satu modal sosial masyarakat lokal dalam lingkup kehidupan etnis Mandar adalah Sayyang Pattu'du. Sayyang Pattu'du (Budaya Massawe Totammaq) adalah sebuah warisan budaya dari Polewali Mandar yang biasanya diadakan dalam rangka merayakan sebuah acara Khataman Alquran (Nurkidam \& Hilmiyah, 2019). Seremoni ini merupakan pagelaran budaya yang sekaligus menjadi wadah bagi etnik Mandar untuk menjalin relasi sosial dalam ritual-ritual kebudayaan. Namun, yang menarik adalah tradisi masyarakat lokal ini tidak hanya digemari oleh warga etnik Mandar saja, tetapi juga disenangi oleh kelompok etnis lain. Tradisi ini kemudian menjembatani hubungan sosial antaretnik dalam masyarakat terutama etnik Bugis, Toraja dan Jawa yang beragama Islam.

Sebagai tradisi masyarakat lokal, seremoni ini biasanya diinisiasi oleh etnik lokal yang umumnya beragama Islam. Perayaan ini dilaksanakan ketika memperingati Maulid (hari lahir Nabi Muhammad SAW) yang dirangkaikan dengan khatam Alquran. Atas kesepakatan warga dan pemerintahan setempat (Desa dan Kelurahan), pagelaran ini membuka ruang untuk semua elemen masyarakat yang ingin berpartisipasi di dalamnya. Dengan kata lain, kelompokkelompok etnik diberi ruang untuk ikut serta. Setiap anggota masyarakat baik Bugis, Jawa maupun Toraja yang beragama Islam berkesempatan yang sama untuk berpartisipasi. Dan terbukti, sebagian besar etnis Bugis telah menjadikan bagian dari budayanya. Bahkan sebagian etnis Jawa dan Toraja setiap saat mengikutkan anak-anaknya dalam atribut tradisi masyarakat lokal tersebut.

Dalam konteks ini, semakin terlihat jelas bahwa ada keterpaduan lintas budaya yang mewarnai kehidupan sosial masyarakat yang bermukim di daerah ini. Dan hal ini juga menunjukkan bahwa Islam sebagai suatu agama, sangat menganjurkan hubungan yang harmoni antara semua umat manusia tanpa 
membedakan latar belakang elemen budaya. Meski berbeda budaya, kelompokkelompok etnis turut serta merayakan tradisi budaya lokal secara bersama dalam ruang-ruang sosial terutama melalui perantara lembaga-lembaga keagamaan dan pemerintahan. Lembaga sosial ini yang semakin menguatkan integrasi sosial lintas etnis. Seperti yang dikemukakan oleh Asdian bahwa salah satu yang menguatkan fungsi modal sosial dalam masyarakat tatkala ada sinergi hubungan antara pemimpin dan lembaga pemerintah dengan masyarakat (state-community relations) (Nasdian, 2014).

Integrasi sosial ini sejalan dengan apa yang digambarkan oleh Ida Bagus Brata. Menurutnya, kearifan lokal yang dimiliki bangsa Indonesia merupakan asset kekayaan kebudayaan masyarakat yang dapat dijadikan sebagai perekat sosial (Brata, 2016). Bahwa Indonesia yang beragam secara identitas kebudayaan dan agama di dalamnya terendap nilai-nilai sosial yang mendorong masyarakat ke ruang-ruang integrasi melalui jaringan sosial yang mereka bentuk. Putnam menyebut bahwa adanya jaringan (network) di dalam kehidupan sosial, akan memperbaiki efisiensi masyarakat karena memfasilitasi tindakan terkoordinasi. Hubungan antaretnis melalui jaringan sosial bersama dengan norma yang disepakati merupakan sumber daya yang merekatkan masyarakat secara luas.

Interaksi yang terjadi secara kontinu dalam masyarakat akan membentuk konsensus yang menurut (Iqbal, 2015), bahwa ada kebutuhan untuk hidup rukun dan komitmen kuat untuk menjunjung norma-norma yang telah disepakati. Sebagaimana formasi sosial yang disepakati dalam pagelaran Sayyang Pattu'du ini, ada sebuah norma (norms) yang dibentuk masyarakat lintas etnik, yang oleh Bourdieau disebut "habitus" atau nilai-nilai sosial yang dibangun dalam masyarakat sebagai hasil internalisasi dalam dunia sosialnya. Dengan kata lain, ia merupakan hasil dari proses sosialisasi nilai yang berlangsung lama di antara anggota masyarakat. Habitus yang dibangun bersama inilah yang memperkuat kebersamaan dan kerekatan di antara kelompok-kelompok sosial (Lee, Elizabeth M. and Rory Kramer, 2012).

Tidak disangkal lagi bahwa kearifan masyarakat lokal ini menjadi salah satu jalan untuk menyatukan beragam budaya. Ia memperkuat kohesi sosial dan relasi sosial di antara kelompok etnis karena seremoni Sayyang Pattu'du tidak hanya menjembatani proses interaksi, tetapi juga sebuah wadah dalam proses penciptaan kerja sama antaretnis di lingkup kehidupan sosial. Hubungan sosial dan kerja sama di antara anggota masyarakat tersebut tidak dimungkiri di dalamnya mengendap pertukaran sosial, kepercayaan sosial serta nilai dan norma yang mendasari hubungan sosial mereka, sehingga memeroleh 
interkonitvitas sosial yang baik di dalam masyarakat (Fernandez and Castilla, 2017).

\section{Asimilasi melalui Pernikahan Lintas Etnis}

I Wayan Mudana menyatakan bahwa jaringan hubungan sosial yang dikembangkan dan didasarkan kedekatan tempat tinggal, kekerabatan, kepentingan sosial, ekonomi, dan budaya merupakan modal sosial yang berfungsi mengintegrasikan masyarakat yang berbeda. Menurutnya, tindak lanjut yang dilihat di proses integrasi ini adalah adanya perkawinan lintas kelompok dan persekutuan berbasis sosial dan budaya (Mudana, 2012).

Tatkala masyarakat yang berbeda telah terintegrasi, maka konsekuensi perbedaan etnis atau identitas budaya tidak akan menjadi penghalang untuk bergumul bersama. Sebagaimana di Wonomulyo, modal sosial yang diciptakan dalam hubungan sosial yang intens dan dalam waktu yang lama oleh warga lintas etnis tersebut telah mengurangi perbedaan yang ada antara individuindividu atau kelompok-kelompok etnis melalui perkawinan campuran. Dalam lembaga pernikahan, mereka tidak lagi memberlakukan penajaman batas identitas. Dengan perkataan lain, perbedaan budaya dan etnik bukan pembatas untuk bersatu padu dalam ikatan keluarga.

Sunyoto Usman dalam Iqbal (2015) menyatakan dalam proses integrasi sosial kelompok-kelompok masyarakat, ada tiga alasan yang menjadi dasar, yakni:

a. Adanya nilai sosial fundamental yang disepakati sebagai acuan normative dan praktis dalam berinteraksi dengan anggota masyarakat.

b. Kesadaran untuk memelihara kesetiaan ganda kepada masing-masing unit sosial sebagai wadah menjalin hubungan sosial dan tetap menjaga kesetiaan kepada unit-unit sosial.

c. Tuntutan bekerjasama dengan orang lain dalam memenuhi kebutuhan sebagai konsekuensi sebagai makhluk sosial.

Alasan-alasan seperti ini yang memperkuat integrasi anggota masyarakat. Mereka berupaya untuk mengurangi perbedaan-perbedaan sosial dan budaya dalam lingkup kehidupan sosial demi memenuhi kebutuhan-kebutuhan mereka. Akibatnya, pernikahan antarkelompok etnis menjadi hal yang lazim dilakukan. Ini yang dimaksudkan oleh (Soekanto and Sulistyowati, 2013) bahwa untuk meningkatkan kesatuan tindakan, sikap dan proses mental, tiap-tiap individu atau kelompok perlu memperhatikan kepentingan dan tujuan bersama. Seperti yang dikemukakan Supriadi Torro bahwa pada tingkat komunitas akan terjadi 
integrasi fungsional antara dua belah pihak yang berbeda sejarah dan ciri sosial budayanya jika di antara mereka saling ketergantungan dan menguntungkan (Torro, 2015).

Pada tahap ini, batas-batas di antara kelompok-kelompok mulai menghilang dan keduanya bergabung menjadi satu kesatuan. Situasi telah mencapai kesamaan-kesamaan selera, gaya hidup, nilai dan norma, minat dan tanggung jawab dan hal ini telah dianggap ideal dalam pencapaian integrasi sosial, yaitu keberbedaan budaya diisi dengan nilai-nilai yang sama, atau pandangan yang sama (Gonzalez-Brambila, 2014). Ini umumnya disebut sebagai asimilasi, yaitu proses di mana orang kehilangan perbedaan budaya mereka dan berbaur dengan masyarakat yang lebih luas (Bucher, 2004). Mereka telah mencapai keselarasan (asimilasi) satu sama lain karena mereka mampu merangkai kesepamahaman budaya satu sama lain.

Menurut Astrid Susanto, suatu komunitas akan berhasil mencapai asimilasi jika: pertama anggota masyarakat merasa bahwa mereka berhasil saling mengisi budayanya, kedua mencapai semacam konsensus tentang norma dan nilai sosial, serta ketiga norma-norma tidak berubah dan mereka mematuhi norma-norma secara konsisten (Susanto, 1983). Proses asimilasi adalah jembatan menuju terciptanya pola budaya baru dalam mengurangi perbedaan di mana budaya ini sebagai satu-satunya fondasi untuk hidup bersama. Dengan demikian, asimilasi ini merupakan tindak lanjut dari modal sosial yang mereka kembangkan. Proses ini merupakan peleburan identitas di mana dua atau lebih individu atau kelompok satu sama lain, melakukan kerja sama sehingga mereka akhirnya menjadi kelompok yang terpadu (Ritonga and Bahri, 2017).

Asimilasi kelompok-kelompok etnis Wonomulyo, Polewali Mandar adalah bagian dari integrasi sosial. Ia merupakan perwujudan dari persepakatan di antara kelompok etnis yang menjunjung norma yang telah disepakati. Bersamaan dengan berkembangnya perkawinan campuran dan modal sosial yang dikembangkan, mereka membangun elemen kekerabatan. Keadaan ini tetap berlanjut sebab dalam proses ini, anggota masyarakat merasa bahwa mereka telah berhasil saling mengisi kebutuhan-kebutuhan mereka dan berhasil menciptakan kesepakatan (konsensus) bersama mengenai nilai dan norma dalam lingkup kehidupan sosial secara luas.

\section{Akulturasi: Jalan yang Semakin Merekatkan Harmoni Sosial}

Akulturasi merupakan proses sosial yang muncul ketika sekelompok orang dengan budaya tertentu sedemikian rupa dipengaruhi oleh unsur budaya 
lain (Azis, 2013). Namun, kehadiran budaya baru tersebut tidak menyebabkan hilangnya identitas budaya asli (Wekke, 2013). Keadaan semacam ini dapat dengan mudah ditemukan di Wonomulyo. Rasa kebersamaan lintas etnis diperkuat oleh akulturasi masyarakat di bidang budaya. Tiap-tiap kelompok etnis, menerima dan menyesuaikan elemen budaya etnis lain dalam lingkup masyarakat sehingga semakin merekatkan harmoni sosial di antara anggota masyarakat.

Pada level praktis, contoh nyata yang bisa diamati pada ranah ini adalah beberapa kelompok Muslim dari etnis Toraja, Bugis, dan Jawa menyatu melalui akulturasi dalam penamatan massal (wisuda setelah khatam Alquran yang dirangkaikan dengan ritual Sayyang Pattu'du) seperti yang telah disinggung sebelumnya. Sebaliknya, etnis lokal (Mandar) mulai menyenangi budaya Jawa khususnya di bidang kesenian. Sama halnya etnis Bugis, secara umum telah mengadopsi budaya etnis Mandar (Sayyang Patt'du) menjadi bagian dari budaya mereka.

Dalam konteks ini, mereka merajuk kebersamaan dalam kerangka akulturasi budaya di mana ada pengakuan masing-masing kehadiran kelompok budaya yang selanjutnya memunculkan penyatuan (Parker et al., 2005). Partisipasi dan penerimaan elemen budaya etnis dalam kehidupan sosial masyarakat dapat dilihat dalam acara keluarga, seperti pernikahan, upacara syukuran atau Khitanan serta acara Maulid. Masing-masing entitas etnik setiap saat memperagakan atau mengonsumsi corak tradisi budaya lain. Dalam pembacaan Bourdieau, hal semacam ini merupakan produk dari habitus yaitu proses reproduksi sosial dan budaya yang menyelaraskan dengan regularitas struktur sosial dalam masyarakat atau produk dari internalisasi nilai-nilai, norma dan kepercayaan yang dimiliki bersama (Jenkins, 2013), (Lee and Kramer, 2013).

Tiap-tiap kelompok etnis dihadapkan dengan elemen budaya masyarakat lintas kelompok sehingga kelompok-kelompok etnis secara bertahap menerima bentuk budaya kelompok lain. Dalam ritual keagamaan misalnya seperti "Maulid Nabi dan Khataman Alquran", meskipun suku Jawa memiliki identitas budaya sendiri tetapi mereka berusaha menyesuaikan diri dengan budaya masyarakat setempat tanpa kehilangan identitas budaya mereka. Demikian juga komunitas lokal, walaupun sebagian besar dari mereka masih menjunjung tradisi dan kebiasaan mereka sendiri, tetapi mereka juga perlahan menyenangi bahkan mengikuti kesenian dan budaya komunitas etnis Jawa seperti 
Campursari dan Kuda Lumping. Begitu pun etnis Toraja dan Bugis, mereka menerima unsur-unsur budaya lokal dalam tatanan kehidupan bermasyarakat.

Dalam perspektif sosiologis, ini merupakan model kerukunan sosial yang dibentuk memalui proses amalgamasi sehingga memberikan kemungkinan yang lebih terbuka pada proses akulturasi dalam jangka waktu yang panjang (Arif, 2014). Masyarakat mengembangkan pola hubungan sosial yang oleh Kunst dan Sam disebut realisasi dari "strategi integrasi akulturasi" yaitu, mereka melibatkan adaptasi terhadap budaya dominan atau minoritas sambil mempertahankan budaya warisan satu sama lain (Kunst and Sam, 2013). Sehingga, meski berbeda kebudayaan, mereka satu sama lain merasa terikat dalam satu kesatuan kelompok.

Dengan demikian, tampak bahwa berbagai kelompok sosial mencapai kerukunan yang tercermin dalam kesatupaduan. Ini berarti bahwa akulturasi berjalan dengan baik dalam masyarakat yang berbeda yaitu mereka berhasil dalam memenuhi kebutuhan-kebutuhan sosial satu sama lain. Bourdieau menyebutnya dengan istilah konsensus tentang norma-norma dan nilai-nilai sosial bersama dalam kehidupan sosial.

Pada konteks ini, penyesuaian atau adaptasi dimaksudkan sebagai strategi untuk memaksimalkan probabilitas keselamatan atau keharmonisan hidup satu sama lain (Mirecki and Chou, 2013). Oleh karena itu, dapat dipahami bahwa dalam akulturasi, ada unsur penerimaan budaya lain yang masuk atau diterima seolah-olah memiliki budaya sendiri yang menjadi kebudayaan bersama dalam rangka merajut kehidupan bermasyarakat yang harmoni.

\section{KESIMPULAN}

Modal sosial adalah elemen penting dalam masyarakat multikultural. Modal sosial yang dikembangkan melalui lembaga-lembaga sosial kemasyarakatan merupakan salah satu jalan yang menjembatani hubungan sosial yang baik. Dari hubungan sosial yang dibangun tersebut, tercipta kepercayaan, norma dan relasi sosial yang mendorong integrasi sosial. Semangat integrasi ini yang melahirkan kerukunan sosial di lingkup kehidupan sosial seperti yang tergambarkan dalam masyarakat multikultural di Wonomulyo.

Berbagai kelompok etnis telah mencapai perpaduan etnis dan penyatuan budaya. Mereka memiliki pemahaman yang sama tentang implementasi ritual keagamaan dan budaya dalam masyarakat yang membuat mereka selaras dalam keberagaman. Sehingga perbedaan etnis, bahasa, budaya tidak membuat mereka saling berseberangan dalam kehidupan sosial. Mereka tetap hidup dalam 
keadaan harmoni, menjunjung tinggi nilai-nilai kebersamaan serta saling menghormati walaupun memiliki perbedaan dalam hal sosial maupun budaya.

\section{DAFTAR PUSTAKA}

Arif, M. (2014) 'Model Kerukunan Sosial pada Masyarakat Multikultural Cina Benteng (Kajian Historis dan Sosiologis)', SosioDidaktika: Social Science Education Journal, 1(1), pp. 52-63.

(2) Azis, D. K. (2013) 'Akulturasi Islam dan Budaya Jawa', Fikrah, 1(2).

(3) Brata, I. bagus (2016) 'Kearifan Budaya Lokal Perekat Identitas Bangsa', Jurnal Bakti Saraswati, 05(01), pp. 9-15.

(4) Bucher, R. D. (2004) 'Diversity consciousness: Opening our minds to people, cultures, and', Management. Pearson, 7(6), pp. 4957.

(5) Ernas, S. (2018) 'Dari Konflik ke Integrasi Sosial: Pelajaran dari Ambon-Maluku', International Journal of Islamic Thought. International Journal of Islamic Thought, 14, pp. 99-111.

(6) Fernandez, R. M. and Castilla, E. J. (2017) 'How Much is That Network Worth? Social Capital in Employee Referral Networks', in Social Capital. Routledge, pp. 85-104.

(7) Field, J. (2010) Modal Sosial. Yogyakarta Indonesia: Kreasi Wacana.

(8) Gonzalez-Brambila, C. N. (2014) 'Social capital in academia', Scientometrics. Springer, 101(3), pp. 1609-1625.

(9) Gunawan, I. (2013) Metode penelitian kualitatif. Jakarta: Bumi Aksara.

(10) Iqbal, I. (2015) Integrasi Sosial Masyarakat Jawa dan Masyarakat Mandar di Kelurahan Sidodadi Kecamatan Wonomulyo. Universitas Negeri Makassar.

(11) Jenkins, R. (2013) Membaca Pikiran Pierre Bourdieu. Yogyakarta: Kreasi Wacana.

(12) Jubba, H. (2019) Kontestasi Identitas Agama: Lokalitas Spiritual di Indonesia. Yogyakarta: The Phinisi Press.

(13) Kunst, J. R. and Sam, D. L. (2013) 'Relationship between perceived acculturation expectations and Muslim minority youth's acculturation and adaptation', International Journal of Intercultural Relations. Elsevier, 37(4), pp. 477-490.

(14) Lee, E. M. and Kramer, R. (2013) 'Out with the old, in with the new? Habitus and social mobility at selective colleges', Sociology 
of Education. Sage Publications Sage CA: Los Angeles, CA, 86(1), pp. 18-35.

Li, Y., Savage, M. and Warde, A. (2008) 'Social Mobility and Social Capital in Contemporary Britain', The British journal of sociology. Wiley Online Library, 59(3), pp. 391-411.

(16) Mahyuddin (2018) 'Dinamika Multikulturalisme Mahasiswa Papua di Yogyakarta'. Yogyakarta: Universitas Gadjah Mada.

(17) Mahyuddin (2019) 'The Crisis of Intolerance and Primordialism in the Name Of Religion in Indonesia: a Case Study Of Pilkada DKI Jakarta at 2017', Kuriositas. IAIN Parepare, (2019), pp. 29-30.

(18) Mirecki, R. M. and Chou, J. L. (2013) 'A multicultural application of attachment theory with immigrant families: Contextual and developmental adaptations', Contemporary Family Therapy. Springer, 35(3), pp. 508-515.

(19) Mudana, I. W. (2012) 'Modal Sosial dalam Pengintegrasian Etnis Tionghoa pada Masyarakat Desa Pakraman di Bali', Jurnal Ilmu Sosial dan Humaniora, 1(1).

(20) Nasdian, F. T. (2014) Pengembangan masyarakat. Jakarta: Yayasan Pustaka Obor Indonesia.

(21) Nurkidam \& Hilmiyah, M. (2019) Alterasi Budaya Sayyang Pattuddu. Parepare: Nusantara Press IAIN Parepare.

(22) Parker, G. et al. (2005) 'Depression in The Chinese: The Impact of Acculturation', Psychological medicine. Cambridge University Press, 35(10), pp. 1475-1483.

(23) Raga, G. \& M. I. W. (2013) 'Modal Sosial Dalam Pengintegrasian Masyarakat Multietnis', Jurnal Ilmu Sosial dan Humaniora, 2(2), pp. 209-221.

(24) Ritonga, A. S. and Bahri, S. (2017) 'Asimilasi Budaya melayu terhadap budaya pendatang di kecamatan senapelan kota pekanbaru', Jurnal Online Mahasiswa Fakultas Ilmu Sosial dan Ilmu Politik Universitas Riau. Riau University, 4(2), pp. 1-15.

(25) Soekanto, S. and Sulistyowati, B. (2013) Sosiologi Suatu Pengantar (Edisi Revisi). Jakarta: RajaGrafindo Persada Jakarta.

(26) Susanto, A. S. (1983) Pengantar sosiologi dan perubahan sosial. Jakarta: Binacipta.

(27) Syafar, D. (2019) 'Pluralisme Agama dalam Pendidikan (Potret Toleransi Beda Agama di SD Negeri 46 Hulontalangi Kota Gorontalo)', Jurnal Kajian Islam Interdisipliner, 2(2). 
(28) Syamsiatun, S. (2014) 'Etika Bertetangga dalam Islam', in Mariani N Noor \& Muhammadsyah, F. S. (ed.) Etika Sosial dalam Interaksi Lintas Agama. Yogyakarta: Indonesian Consortium for Religious Studies.

(29) Torro, S. (2015) Integrasi Sosial dan Asimilasi. Makassar: Badan Penerbit Universitas Negeri Makassar.

(30) Usman, S. (2015) Esai-Esai Sosiologi Perubahan Sosial. Yogyakarta Indonesia: Pustaka Pelajar.

(31) Varanida, D. (2016) 'Komunikasi dalam Integrasi Sosial Budaya antar Etnis Tionghoa dan Pribumi di Singkawang', Jurnal Ilmu Komunikasi, 14(1).

(32) Wekke, I. S. (2013) 'Islam dan adat: tinjauan akulturasi budaya dan agama dalam masyarakat Bugis', Analisis: Jurnal Studi Keislaman, 13(1), pp. 27-56. 